\title{
Energy Internet Comprehensive Benefit Evaluation System and Operation Strategy
}

\author{
Bai Hongkun ${ }^{1, a}$, Wang Jiangbo ${ }^{1, b}$, Deng Fangzhao ${ }^{1, c}$, Liu Dunnan²,d, Wang

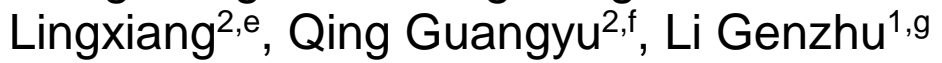 \\ ${ }^{1}$ State Grid Henan Economic Research Institute \\ ${ }^{2}$ North China Electric Power University \\ a1420254015@qq.com, b409227228@qq.com, c1016329674@qq.com, dliudunnan@163.com, \\ e3217849263@qq.com, ${ }^{\dagger} 13263462372 @ 163 . c o m$
}

\begin{abstract}
Keywords: "Internet +"; Energy Internet; Grid benefit evaluation
Abstract. With the introduction of "Internet +" series of policies, the development of energy Internet has reached a new climax. Based on the research of domestic and foreign literatures on the development of energy Internet, this paper introduces the Energy Internet benefit assessment and development model in combination with the development of domestic Energy Internet. Based on status quo, contacting theory with practice, using the calculation model and calculation method in the theoretical results, combined with the Energy Internet development trend, and on the basis of qualitative quantitative analysis, establish Energy Internet comprehensive benefit evaluation system and operation strategy. Based on the characteristics and policies of the power grid corporation, this paper puts forward some Suggestions and plans for the service and operation of the energy Internet under the power grid corporation.
\end{abstract}

\section{Introduction}

In July 2015, the state council issued the "Internet +" smart energy (energy Internet) initiative on The Positive Promotion of "Internet + "Action Guidance. In February 2016, the national development and reform commission (NDRC), the energy bureau and the ministry of industry jointly issued guidance of promoting the development of the" Internet + "wisdom energy, which clarifies the development path and thinking of the future energy Internet and the top ten key tasks of China and the future. In July 2017, the national energy administration announced the first batch of 55 demonstration projects of the Internet + smart energy and energy Internet, and the progress of these projects has been closely watched. The start and the construction of Energy Internet demonstration projects impact on the traditional energy development and utilization, change the domination and control pattern according to industry and according to domain, inspire a lot of social forces and the influx of capital, promote the related business model, the innovation of the technology and equipment manufacturing process. It should be said that the energy Internet is a comprehensive system of multi-discipline, multi-industry, multi-field, multi-chain and multi-control subject.

Based on this, this paper will make full use of domestic and foreign literature on the development of Energy Internet, and this project proposes the technology of Energy Internet research. Secondly, by analyzing the market mechanism and the characteristics of trading mechanism, combined with the comprehensive evaluation method, it provides a solid theoretical foundation for the research of energy Internet operation strategy. Finally based on the status quo, contacting theory with practice, using the calculation model and calculation method in the theoretical results, combined with the energy development trend of the Internet, and on the basis of qualitative quantitative analysis, establish Energy Internet comprehensive benefit evaluation system and operation strategy. Based on the characteristics and policies of the power grid corporation, this paper puts forward suggestions on the service and operation plan of power network construction.

Research of energy on the Internet could be used to establish and improve the energy Internet market trading system, help to promote energy Internet business model innovation and help energy 
operators, power generation enterprises, power grid companies and users to explore energy form of business and management mode, improve enterprise operational management level.

\section{Research status of energy Internet}

The construction of Energy Internet was proposed in 2004 when The Economist published "Building The Energy Internet", which first proposed the construction of the Energy Internet (Energy Internet). In December 2008, the German federal economic and technology department launched a technology innovation promotion programs, with basis of information and communication technologies (information and communication technology, ICT) to build the future energy systems. In 2011, Europe launched the Future Internet for Smart Energy (FINSENY) project. In 2010, Japan launched the "Smart Energy Community" program to conduct research in areas such as energy and smart grids.

The flexibility and interconnectedness and many other advantages of the Energy Internet determine the energy platform with the platform of the whole society, commercial and user service, thus to promote the emergence of many new trading patterns. In Europe there is a peer-to-peer (P2P) transaction that allows free energy transactions between users. Many European countries are beginning to test project, such as the Open Utility Piclo tests of British, the Vandebron end-to-end trading platform of Dutch, as well as Peer Energy Cloud project development based on virtual markets end-to-end power trading in Germany.

At present, there are different priorities for energy Internet in foreign countries, but all of them apply Internet technology to the energy system. They put a centralized, one-way, producers control energy systems into a large number of distributed with less centralized new energy and interaction with the energy systems of more consumers, in order to increase the share of renewable energy, realization of multiple energy effective and efficient use of the Internet. ${ }^{[1]}$

In the $1980 \mathrm{~s}$, the former president of Tsinghua university Gao Jingde put forward "CCCP" (Modern power system is the deep integration of computer, communication, control and power system and power electronics technology.) concept. In June 2014, led by China electric power research institute for state grid corporation based prospective project "Energy Internet technology architecture study", strive to build energy future internet architecture, set up the corresponding Energy Internet research platform. In 2015, the government work report launched the "Internet +" action plan. In April 2016, the national development and reform commission and bureau of energy release "Revolutionary Energy Technology Innovation Action Plan (2016 2030)".

Domestic energy Internet has been the government and research institutions at all levels attach great importance to, and obtained the financial support of governments and enterprises, the concept of energy Internet and technology has caused more and more attention in China. And various pilot projects are under way.

\section{Analysis of energy Internet market.}

Analysis of main body of energy Internet market. The energy Internet is actually composed of four complex network systems, namely power systems, transportation systems, natural gas networks and information networks. The connection is shown in figure 2-1. 


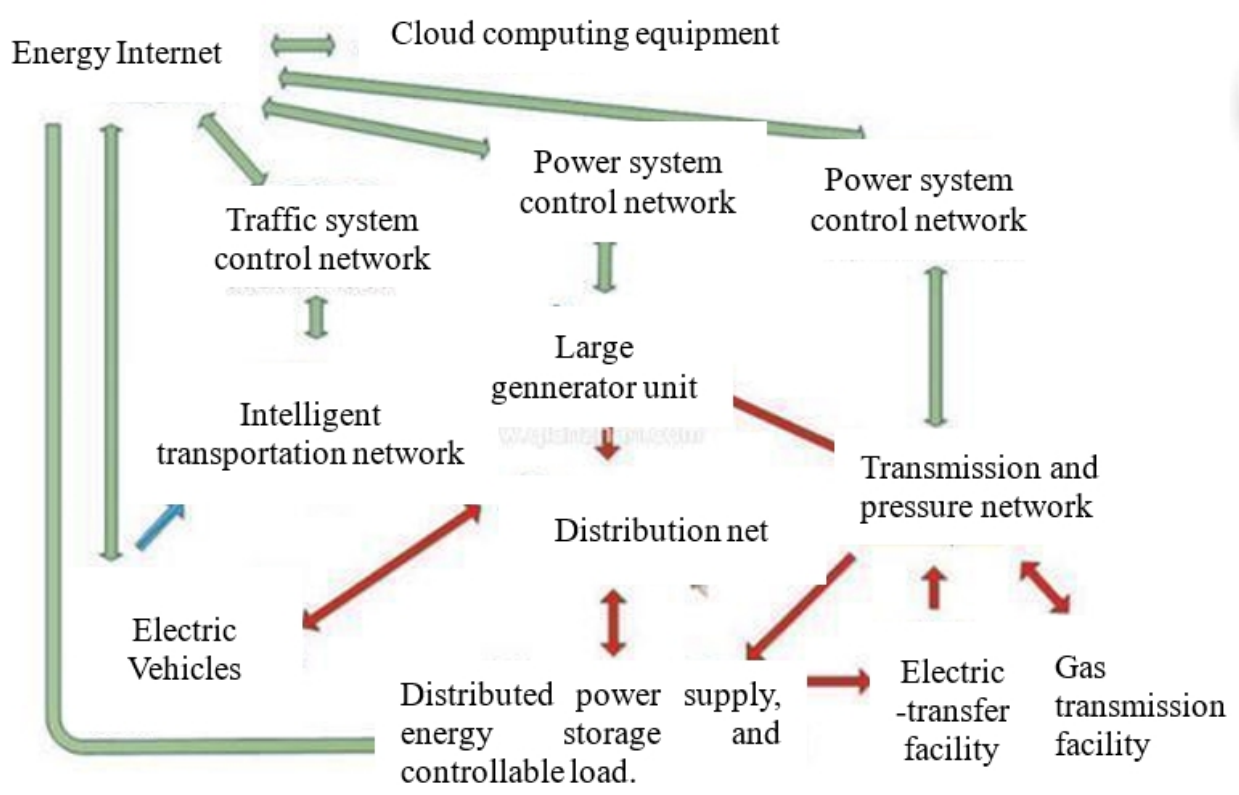

Fig. 2-1 energy Internet market structure.

In our country, considering the present development of electric power, heat and the future development direction of energy revolution, the energy may be the body of the Internet market construction are: electric power company, power generation (thermal power plant), sell electricity companies, property companies, a third party and so on. There are advantages and disadvantages to the construction and operation of Energy Internet dominated by different operating entities. There are advantages and disadvantages to the construction and operation of energy Internet dominated by different operating entities. In the present industrial environment and user habits, different modes are different from the feasibility, as shown in table 2-1 below.

Table 2-1 comparison of different operation modes

\begin{tabular}{|c|c|c|c|}
\hline $\begin{array}{l}\text { The operational } \\
\text { principal }\end{array}$ & advantage & disadvantage & feasibility. \\
\hline $\begin{array}{l}\text { Electric power } \\
\text { company }\end{array}$ & $\begin{array}{l}\text { sufficient power supply, capital, } \\
\text { technology and sufficient } \\
\text { personnel, users use inertia. }\end{array}$ & $\begin{array}{l}\text { the restriction of the national } \\
\text { policy }\end{array}$ & 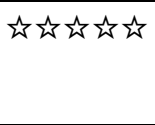 \\
\hline $\begin{array}{l}\text { The regional energy } \\
\text { station }\end{array}$ & $\begin{array}{l}\text { directly produce cold, heat, } \\
\text { electricity, capital, technology, } \\
\text { and sufficient personnel }\end{array}$ & $\begin{array}{l}\text { be restricted by power } \\
\text { dispatching. }\end{array}$ & 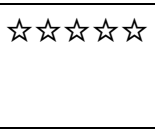 \\
\hline $\begin{array}{l}\text { Electric sells } \\
\text { company }\end{array}$ & $\begin{array}{l}\text { in line with the industrial policy, } \\
\text { the market management means }\end{array}$ & $\begin{array}{l}\text { without the stable source of } \\
\text { hot and cold electricity } \\
\text { supply, and the } \\
\text { competitiveness is weak. }\end{array}$ & 弐方 \\
\hline $\begin{array}{l}\text { The property } \\
\text { company }\end{array}$ & $\begin{array}{l}\text { the user information, the } \\
\text { construction and installation of } \\
\text { the distributed power }\end{array}$ & $\begin{array}{l}\text { without the stable source of } \\
\text { hot and cold electricity } \\
\text { supply, and the } \\
\text { competitiveness is weak. }\end{array}$ & 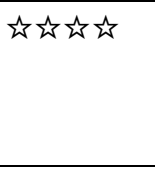 \\
\hline $\begin{array}{l}\text { The third party } \\
\text { company }\end{array}$ & $\begin{array}{l}\text { marketization management } \\
\text { means, the profit model is } \\
\text { flexible }\end{array}$ & $\begin{array}{l}\text { without the stable source of } \\
\text { hot and cold electricity } \\
\text { supply, and the } \\
\text { competitiveness is weak. }\end{array}$ & 计动 \\
\hline
\end{tabular}

In general, power generation enterprise actively layout in the electricity sales market, and to rely on existing electricity and heat production conditions, strong financial and technical support. The power generation enterprises have taken the lead in the development of the cold and hot electric hybrid energy supply market, and become the construction and operation main body of the application of the future cold and hot electric hybrid energy scale application. While grid companies and property companies each have their own advantages and disadvantages, which will become the most powerful competitors of power generation enterprises. 
Analysis of energy Internet market mechanism. In order to support the diversified business models in the energy Internet era, a reasonable and flexible market system is needed to be constructed and the corresponding supporting mechanism is to designed. The energy Internet needs to realize the mutual coupling and standardization trading of various energy forms on the physical plane, and the spot and futures market of energy need to be constructed on the value plane. At the same time, the era of the energy Internet will also generate markets other than the energy market, such as carbon trading, green currency, energy efficiency, and quota trading.

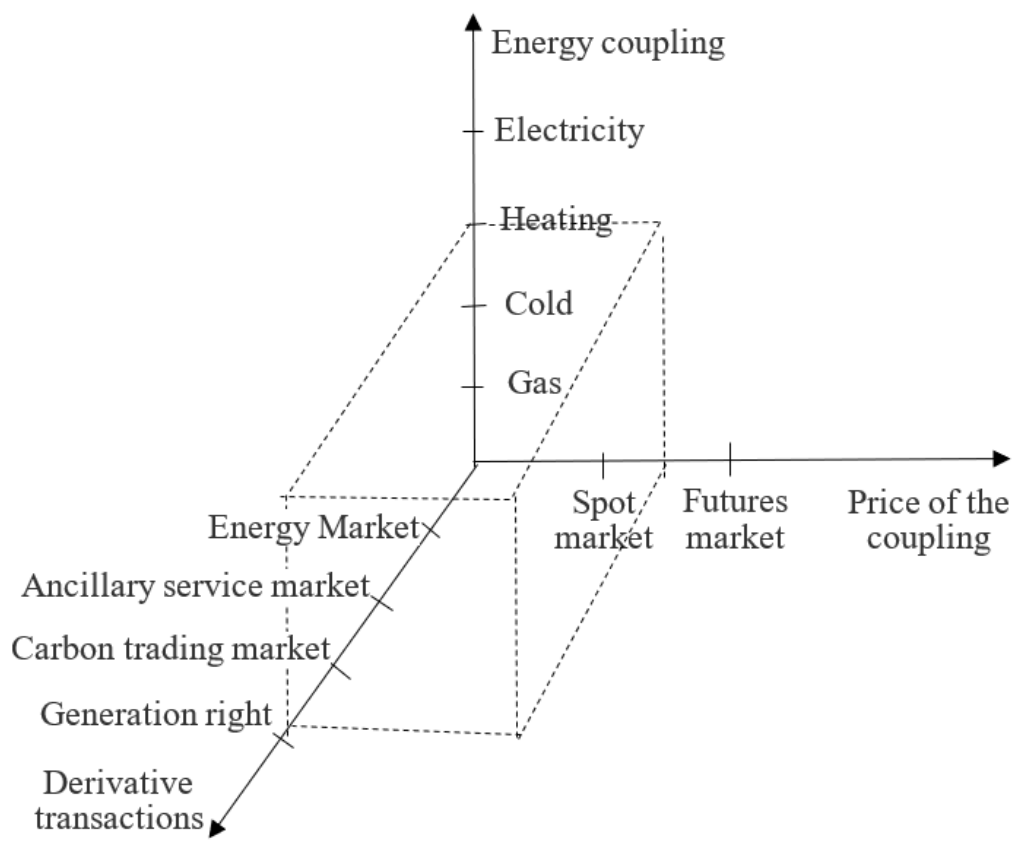

Fig. 2-2 framework of energy Internet market frame.

In the framework of such a power coupling, coupling price, derivatives "trinity" energy Internet system, energy trading will also present a three-dimensional, diversified and personalized characteristic, the market structure, trade body, trade patterns, trade goods, the market supervision and so on various aspects all have important changes.

\section{Establishment of comprehensive evaluation system of energy Internet.}

As countries promote the building of energy of the Internet, and evaluate the energy level of Internet development has become a necessary work, set up evaluation index system of energy on the Internet is to carry out the important foundation and basis of the assessment. Specifically as follows: he is measure the important basis of the energy level of Internet development, is an important evaluation of social benefits based on grid development, is one of the important guidance based on the Energy Internet development planning.

\section{Indicator system.}

Combined with the feature concepts and typical of Energy Internet, according to the principle of establishing evaluation index system of Energy Internet, considering energy production, service, consumption as well as the interests of the state and other social roles; considering planning, construction, operation, and other links of Internet Energy, considering economic, energy, environmental, social and engineering the five point of view, set up index system, as shown in table 3-1. 
Table 3-1 energy Internet evaluation index system.

\begin{tabular}{|c|c|c|}
\hline & Primary index & Secondary index. \\
\hline \multirow{31}{*}{$\begin{array}{l}\text { Comprehensive evaluation } \\
\text { system of energy Internet }\end{array}$} & \multirow[t]{7}{*}{ Economic Angle S1 } & Investment payback period. \\
\hline & & Input-output ratio \\
\hline & & Construction cost \\
\hline & & Operation and maintenance cost \\
\hline & & Management service cost \\
\hline & & Standby cost \\
\hline & & Subsidies income \\
\hline & \multirow[t]{6}{*}{ Energy efficiency 2} & Primary energy ratio \\
\hline & & Primary energy consumption. \\
\hline & & Clean energy efficiency. \\
\hline & & Clean energy ratio \\
\hline & & Thermoelectric exchange rate \\
\hline & & $\begin{array}{l}\text { Comprehensive } \\
\text { utilization. }\end{array}$ \\
\hline & \multirow[t]{6}{*}{ Environmental Angle S3 } & Pollutant emission. \\
\hline & & Pollutant reduction \\
\hline & & Pollution control costs \\
\hline & & Discharge penalty fee \\
\hline & & Clean-up cost \\
\hline & & Pollutant hazard index. \\
\hline & \multirow[t]{6}{*}{ Social Angle S4 } & User satisfaction. \\
\hline & & Corporate image revenue \\
\hline & & Corporate publicity expenses \\
\hline & & Related industry impact index. \\
\hline & & Employment benefits \\
\hline & & New energy vehicle occupancy. \\
\hline & \multirow[t]{6}{*}{ Engineering Angle S5 } & Technical feasibility. \\
\hline & & Engineering safety \\
\hline & & Project scalability \\
\hline & & Wide - range sharing. \\
\hline & & Time limit for a project \\
\hline & & Project life \\
\hline
\end{tabular}

The quantitative indicators can be directly calculated, and the qualitative indexes are graded according to the project constraints between 0 and 1 so as to comprehensively evaluate the energy Internet. The technical feasibility, draw lessons from foreign level of nine technical maturity standard according to the technology development process for the division of technical maturity, energy internet-related technology maturity hierarchies are given, specific descriptions are shown in table 3-2 below.

Table 3-2 classification of mature service level of energy Internet technology.

\begin{tabular}{|c|c|}
\hline Technical maturity level & description \\
\hline Level 1 & Discover the fundamentals of technology. \\
\hline Level 2 & Give the technical concept and application model. \\
\hline Level 3 & $\begin{array}{l}\text { The key functional modules of the technology are } \\
\text { verified by experiments. }\end{array}$ \\
\hline Level 4 & Verify technical feasibility in laboratory environment. \\
\hline Level 5 & Verify technical feasibility in simulation environment. \\
\hline Level 6 & $\begin{array}{l}\text { The feasibility of verification technology under system } \\
\text { integration in simulation environment. }\end{array}$ \\
\hline Level 7 & $\begin{array}{l}\text { Verify the technical feasibility in the actual operating } \\
\text { environment. }\end{array}$ \\
\hline Level 8 & Through the testing and verification of the actual system. \\
\hline Level 9 & It is verified in the actual application environment. \\
\hline
\end{tabular}


The index system includes economic benefit index, social benefit index and environmental performance index. Economic indicators include unit using energy consumption index, energy intensity, electricity intensity, reduce the energy consumption of unit rate index, energy consumption per unit GDP decreased rate, the added value of unit area production energy consumption rate; social benefit indicators include comprehensive energy consumption per capita, non-fossil energy consumption ratio; environmental indicators include greenhouse gas emissions, unit GDP carbon dioxide emissions, gross area pollution reduction evaluation indexes such as reduce carbon dioxide emissions rate, and unit GDP chemical oxygen demand (cod) emissions, sulfur dioxide emissions of unit GDP, unit GDP particulate matter (PM10) emissions, unit GDP index nitrogen oxide emissions. Establishment of comprehensive evaluation model of energy Internet. Through the analysis of the above indicators system, it can be seen that the indexes are not independent from each other, and it is difficult to determine their weight in the energy Internet evaluation model through traditional methods. We uses structure modeling method to explain the Energy Internet evaluation index system, and concluded the influence of the relationship between different indicators. Then we get the weight of different indexes using analytic hierarchy process (ahp) thinking. Finally through the normalized processing, we carry on the comprehensive evaluation of the Energy Internet.

The specific steps are as follows.

Step 1: construct system factor set according to the Energy Internet evaluation index system and record it as

$$
\mathrm{N}=\left\{e_{i} \mid \mathbf{i}=1,2, \ldots, n\right\}
$$

Step 2: determine the other indicators directly affected by each indicator, then establish A directed relationship between the indicators and establish the consciousness model, and establish the adjacency matrix A. The specific elements are

$$
a_{t j}=\left\{\begin{array}{l}
1, i \neq j \\
0, i=j
\end{array}\right.
$$

Step 3: if $\mathrm{k} \leq \mathrm{n}-1$, and it satisfies the condition

$$
(\mathrm{A}+\mathrm{I}) \neq \cdots \neq(A+I)^{k} \neq(A+I)^{k+1}
$$

Then the accessible matrix $\mathrm{M}$ is.

$$
\mathrm{M}=(\mathrm{A}+\mathrm{I})^{k}
$$

Where I is the identity matrix.

Step 4: based on the accessible matrix, the standard method or practical method is used to divide and determine the index level to form a hierarchical structure model, which is represented by a multi-level recursive graph.

Step 5: according to the relevant theories and experiences, we can explain the multi-level recursion graph and get the interpretation structure model. Compared explanation structure model with the existing experience and practice, if not, return to step 1 and the binary relation about the elements and explanation structure model modification, if accord with each other, then continue.

Step 6: experts give the scores from $1 \sim 9$ scale according the relative importance of each target. Relative to the same elements, 1 said the lower two factors have the same importance, with the increase of scale values, the former is more important than the latter's degree also increases, 9 means comparing the two factors, the former is extremely important than the latter. Construct multiple judgment matrices based on the score.

Step 7: calculate the weight of each factor using the weight coefficient.

The weight coefficient is 


$$
w_{t}=\frac{\sqrt[n]{\prod_{j=1}^{n} b_{\mathrm{ij}}}}{\sum_{i=1}^{n} \sqrt[n]{\prod_{j=1}^{n} b_{1 j}}}
$$

According to the weight, have a consistency check on the results. The test formula is $B W=\Gamma W$

$$
\mathrm{CI}=\frac{\gamma_{\max }-\mathrm{n}}{n-1}
$$

In the formula, $\mathrm{B}$ is the n-order judgment matrix, and $b_{\mathrm{ij}}$ is the corresponding element in the judgment matrix, $\gamma$ is the characteristic root in the judgment matrix, and $\gamma_{\max }$ is the maximum characteristic root of the matrix. If $\mathrm{CI}<0.10$, the consistency test is adopted.

Step 8: using the time weight and superposition weight respectively calculates the evaluation index of each layer respectively weight are calculated respectively. Finally, the weight of each evaluation index and the normalized score $w_{i}$ are given.

Step 9: normalizes the quantization index $x_{i}$ in the indicator system and obtains the normalized value $y_{i}$, and then deal the cost and other indicators which need to be minimized using NEG, and obtains the standard value $c_{i}$ of the indicator $\mathrm{i}$, which is

$$
\begin{gathered}
y_{i}=\frac{x_{i}-\min x_{j}}{\max x_{j}-\min x_{j}} \\
c_{i}= \begin{cases}y_{t}, & \text { Maximizing index } \\
1-y_{i}, & \text { Minimizing index }\end{cases}
\end{gathered}
$$

Step 10: calculate the overall weight.

$$
\mathbf{G}=\sum_{I=1}^{n} w_{i} c_{i}
$$

\section{Research on energy Internet operation strategy}

Traditional "source-network-hold-storage" operation strategy. In the traditional sense, the power system "source - net - load - store" coordination optimization model and technology refers to the power supply, power grid, and load and energy storage four parts through a variety of means of interaction, more economic, efficient and safely improve the dynamic balance ability of power system, so as to realize the mode of the maximum utilization of energy resources and technology, the model is a operation mode of the overall solution includes "power supply, power grids, load and energy storage". It includes: source - source complementary, source - network coordination and source - net nuclear interaction.

\section{Coordinated and optimized operation mode of energy Internet.}

the basic structure of the coordinated and optimized operation mode of energy Internet. Under the background of energy Internet, the coordination and optimization of "source network load and storage" has a deeper meaning; "Source" includes oil, electricity, natural gas and other energy resources; "Network" includes power grid, oil pipeline network, heating network and other resources 
network; "load" includes not only the power load, but also the various energy needs of users; "Storage" mainly refers to various storage facilities and storage methods of energy resources.

The main structure of the energy Internet "source-network-load-storage" coordinated and optimized operation model is shown in 4-1.

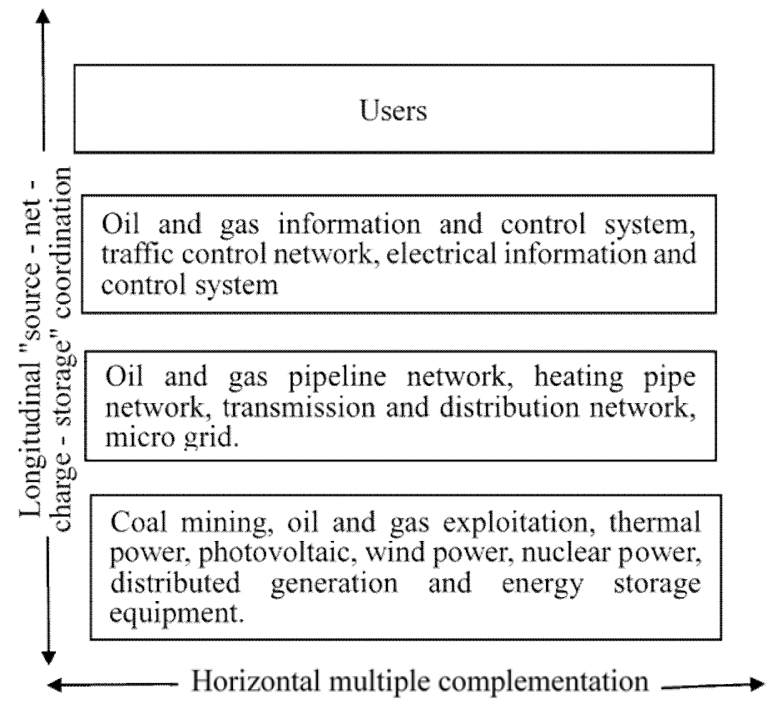

Fig. 4-1 coordinated and optimized operation mode of the energy Internet "source-network-load-storage"

the basic method of coordinated and optimized operation mode of Energy Internet.

The coordination and optimization operation mode of the energy Internet is divided into four parts, as shown in figure 4-2 in chronological order.

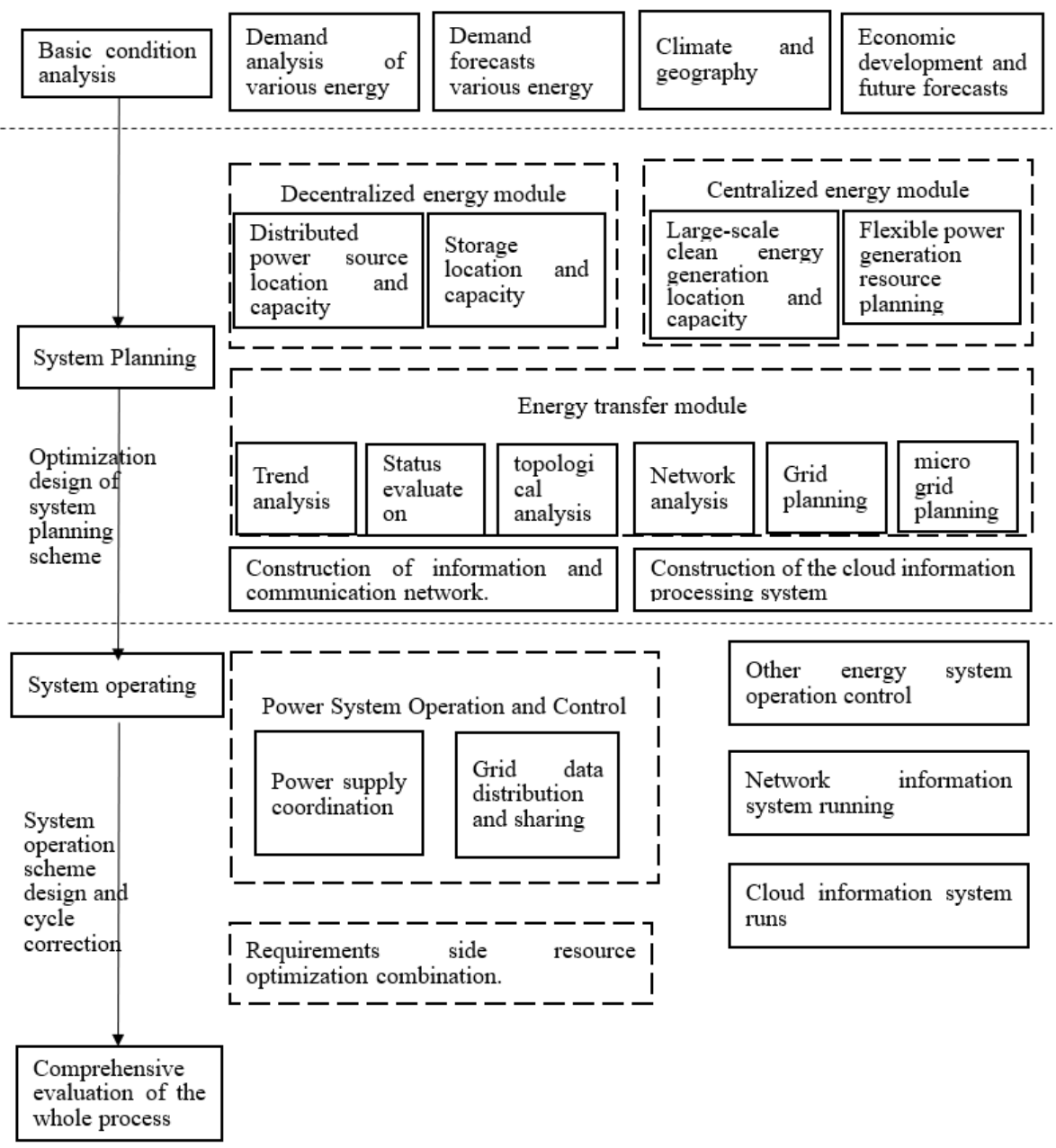

Fig. 4-2 basic flow of the "source-network-load-storage" operation mode of energy Internet. 
First, analyze the basic conditions. Before system planning design, the system operators need to carry on the assessment of the status quo and future development trend prediction of the construction of the target area, and on this basis, combine with geographic information system (GIS), physical information fusion system (CPS) and other technology to predict the variety of energy demand for the user, and analyze current energy supply channels and ways.

Then, the system plan is based on the data information obtained by the basic condition analysis, and selecting the appropriate location to carry out the construction of decentralized energy module and centralized energy module. The decentralized energy module is dominated by distributed power supply and its supporting facilities. The centralized energy module is mainly based on large-scale clean energy generation and flexible power generation resources. In the planning stage, the future system operation needs should be fully taken into consideration. The decentralized energy module should provide an effective supplement to the centralized energy module, after achieving the internal balance of energy supply and demand. At the same time, the system operators need to complete the construction of energy transmission modules to provide energy channels connecting users to centralized and decentralized energy modules. The decentralized energy module should be connected with the main energy system through the micro grid, and the micro grid technology plays a buffer and optimization role. In addition, system operators have to build information communication network and the cloud information processing system, to calculate the feasibility of system planning and make selection and optimization in multiple scheme, and collect energy information and put forward a optimized system operation scheme.

During system operation, the system operator collects all users' energy useing information and basic data of the energy supply side through information communication network, provides users with optimized energy consumption scheme through the analysis of information processing system in the cloud processing, and guides users active tracking clean energy power generation electricity output by reasonable price mechanism and demand side response measures. At the same time, design rational dispatching order and output arrangements according to the data information of generation side, combine with the dispersion energy module "spontaneous for private use, Internet access allowance," mode, implement system of bilateral coordination optimization and the double adaptive process. Meanwhile, we should give full play to the link effect of power system and optimize the operation of other energy modules (such as heating, water supply, gas supply, etc.).

In 3-5 years of the completion of the Energy Internet operations project, we need to evaluate the project's operation situation analysis, build index system including renewable energy use efficiency, power supply reliability and equipment utilization, compare and analyze projects with the comprehensive evaluation method, and find the project defects and correct them circularly.

\section{Coordinated and optimized operation strategy of energy Internet.}

\section{Mode selection.}

Energy Internet commercial operation can take many mode, power grid companies, power companies, property companies, and industrial park can invest in the construction of the Energy Internet, for people are not good at energy management and investment, operation also can entrust a third party.The common construction and operation mode of Energy Internet is shown in the following figure. 


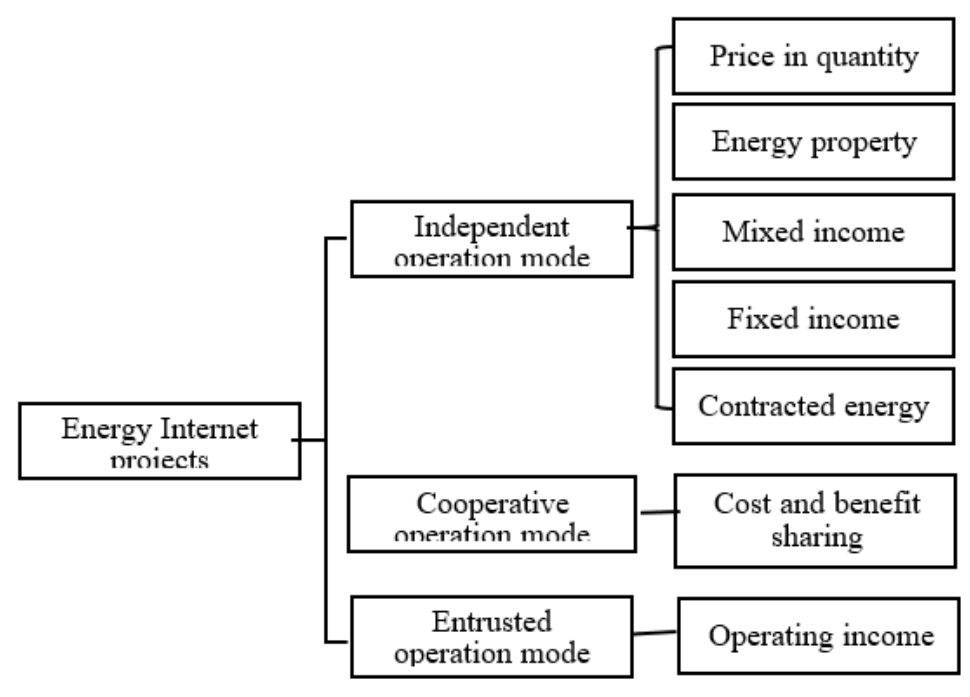

Fig. 4-3 hybrid energy supply operation mode of cold and hot electricity.

\section{Implementation path of energy Internet investment operation mode.}

Energy Internet investment forms changed from the "independent investment" to the "joint venture" and to the "financing", according to the energy development trend of Internet and business point of view, can be divided into early stage of development, medium-term large-scale development stage, later stage of commercial development. of development. After a comprehensive comparison of the advantages and disadvantages of various investment operation modes, the investment and operation mode of energy Internet under different development stages is shown in table 4-1.

Table 4-1 investment mode of each stage of energy Internet development.

\begin{tabular}{|c|c|c|}
\hline $\begin{array}{l}\text { Development } \\
\text { stage }\end{array}$ & $\begin{array}{l}\text { operation } \\
\text { mode }\end{array}$ & remarks \\
\hline $\begin{array}{l}\text { Early stage of } \\
\text { development }\end{array}$ & $\begin{array}{l}\text { Independent } \\
\text { investment } \\
\text { mode } \\
\text { combined } \\
\text { operation and } \\
\text { maintenance } \\
\text { mode }\end{array}$ & $\begin{array}{l}\text { 1. The early stage of development, because the income } \\
\text { allocation mechanism is not sound, investment prospects } \\
\text { uncertain, the government should promote deep-pocketed } \\
\text { energy Internet or power grid enterprise investment project, } \\
\text { in order to shorten the payback period of money or improve } \\
\text { profit margins, so the investment in construction stage } \\
\text { adopts independent investment mode; } \\
\text { 2. In the operation and maintenance phase, using the joint } \\
\text { operational mode, the company needs to recruit professional } \\
\text { and technical personnel responsible for distributed power } \\
\text { system operations, in human resources, invest a lot of money } \\
\text { on equipment, spare parts and materials, the economy is bad, } \\
\text { so the joint operational mode, and energy service companies } \\
\text { and gas supply companies to cooperate, the energy service } \\
\text { companies will be responsible for the operational issues of } \\
\text { the system. }\end{array}$ \\
\hline $\begin{array}{l}\text { Medium-term } \\
\text { large-scale } \\
\text { development } \\
\text { stage }\end{array}$ & $\begin{array}{l}\text { Cooperate } \\
\text { with the } \\
\text { equipment } \\
\text { manufacturer } \\
\text { (park) } \\
\text { investment } \\
\text { mode + } \\
\text { combined }\end{array}$ & $\begin{array}{l}\text { 1. In the energy Internet investment large-scale development } \\
\text { stage, in order to reduce the pressure on companies to invest } \\
\text { money, in the money into the biggest equipment } \\
\text { procurement procedures in the form of cooperation with } \\
\text { equipment suppliers, implement company's business } \\
\text { expansion and equipment suppliers to grab market share } \\
\text { win-win situation; } \\
\text { 2. In the operation and maintenance stage, the joint operation }\end{array}$ \\
\hline
\end{tabular}




\begin{tabular}{|l|l|l|}
\hline & $\begin{array}{l}\text { operation and } \\
\text { maintenance } \\
\text { mode }\end{array}$ & $\begin{array}{l}\text { and maintenance mode is also adopted to cooperate with } \\
\text { energy service enterprises and gas supply companies, and the } \\
\text { energy service enterprises shall be responsible for the } \\
\text { operation and maintenance of the system. }\end{array}$ \\
\hline $\begin{array}{l}\text { Later stage of } \\
\text { commercial } \\
\text { development. }\end{array}$ & $\begin{array}{l}\text { Cooperate } \\
\text { with energy } \\
\text { service } \\
\text { enterprises } \\
\text { and other } \\
\text { cooperative } \\
\text { investment } \\
\text { mode } \\
\text { combined } \\
\text { operation and } \\
\text { maintenance } \\
\text { mode. }\end{array}$ & $\begin{array}{l}\text { Investment in energy Internet commercialization stage of } \\
\text { development, in order to improve the efficiency of the } \\
\text { company's overall business investment, alleviate the } \\
\text { investment risk of the enterprise, in the distributed energy } \\
\text { investment construction stage and system operational stage } \\
\text { companies with a professional energy service companies and } \\
\text { gas cooperation, only invest does not undertake the } \\
\text { construction of concrete and operational work. }\end{array}$ \\
\hline
\end{tabular}

\section{Conclusion}

Combined with the feature concepts and typical of Energy Internet, according to the principle of establishing evaluation index system of Energy Internet, considering energy production, service, consumption as well as the interests of the state and other social roles; considering planning, construction, operation, and other links of Internet Energy, considering economic, energy, environmental, social and engineering the five point of view, we establish the Energy Internet comprehensive benefit evaluation index system. It is one of the important basis and measure of the Energy Internet development level, and is an important evaluation measure of social benefits based on grid development, is also the important guidance of energy Internet development planning.

Typical energy Internet business model combined with the future development trend, and exploring new energy Internet business model, is advantageous to the energy construction and development of the Internet market. At the same time, combining the traditional "source - net - load storage" operation strategy to discover energy Internet operating strategy, consider traditional operation strategy, analysis the influencing factors, and explore feasible scheme, design energy Internet investment operation implementation path, speed up the construction of commercial investment.

Energy of the Internet as a new type of energy system, its performance evaluation is a complicated system problem, the accurate assessment will be more research is needed, the need for long-term investment, so the energy Internet benefit evaluation is put forward. First of all, we should establish an index system for evaluating the efficiency of energy Internet. Provide a more comprehensive and objective assessment basis. Index system need to comprehensive evaluate the implementation of the energy Internet benefit in our country from the aspect of multiple objective, and considere various factors to adapt to different levels of different main body and different types of projects benefit assessment requirements. Secondly, establish the energy Internet maturity model. Reference to the thought of the smart grid maturity model, we can establish suitable maturity model of the Energy Internet, and conside technologies in combination with energy, demonstration and business development present situation, to evaluate the development stage of the Energy Internet from multiple dimensions. Which can be helpful to analyze energy path, the characteristics and gap on the development of the energy Internet in different countries and different enterprises. Determine the key performance indicators and implement of each development path of Energy Internet, and encourage, guide and support the development and investment of the Energy Internet, and regularly carry out maturity assessment of the Energy Internet. Finally, establish the energy Internet benefit evaluation mechanism and platform. The platform can manage the energy Internet project, evaluate the whole 
process of project implement, and construct measureds of performance evaluation based on cloud. Which provides a typical case and benchmarking project for large, medium and small energy construction of the Energy Internet, convenient and quick to carry out the performance evaluation, and combines the technique of big data to make transverse comparison and to achive efficiency supervision.

\section{References}

[1] Zhou Xiaoxin, Zeng Rong, Gao Feng, Qu Lu. The Development Status and Prospect of Energy Internet [J]. China Science 2017-2(149-170).

[2] Sun Hongbin, Guo Qinglai, Pan Zhaoguang. Energy Internet: Concept, Architecture and Forward Outlook [J]. Power System Automation. 2015 (10).

[3] Jiang Ling, Yuan Yue, Wang Zheng, Wang Shouxiang. Energy Internet Evaluation Index and Evaluation Method of Smart Grid Innovation Demonstration Zone [J]. Electric Power System and Automation Journal.2016(1)

[4] Wang Yiming. Global Energy Internet Concept and Outlook [J]. China Power 2016-49-3.

[5] Yang Ping, Chen Ying, Zhang Jingwei, Kang Longyun, Luo Zhizhao. Study on Energy Efficiency Evaluation Index System of Energy Internet in The Park [J]. Information Science, 2017.25.157.

[6] Ming Zeng, Yang Yongqi Liu Duinan, Ceng Bo, Ouyang Shao, Hai-Ying Lin, Han. Energy Internet "Source - Net - Load - Store" Coordination Optimization Model and Key Technology [J]. Power Grid Technology (2016) 01-0114-11.

[7] Zeng Ming, Yang Yongqi, Li Yuanfei, Zeng Bo, Cheng Jun, Bai Xuanxiang. New Energy Power System Operation Model and Key Technologies in The Energy Internet Background [J]. Journal Of China Electrical Engineering Engineering.

[8] Jiang Ling, Yuan Yue, Wang Zheng, Wang Shouxiang. Energy Internet Evaluation Index and Evaluation Method of Smart Grid Innovation Demonstration Zone. Power System and Automation Journal 2016(01).

[9] Tian Shi, Luan Wenpeng, Zhang Dongxia, Liang Qihao, Sun Yaojie. Energy Internet Technology Form and Key Technology [J]. Journal of Chinese Electrical Engineering Engineering. (2015) 14-3482-13.

[10] Dong Chaoyang, Zhao Junhua, Wen Futie, Xue Yusheng. From Smart Power Grid to Energy Internet: Basic Concepts And Research Framework [J]. Power System Automation 2018-38-15. 